\title{
PROJETOS DE EXTENSÃO COMO FERRAMENTA PARA UMA MAIOR PARTICIPAÇÃO DE MULHERES NOS CURSOS DE CIÊNCIAS EXATAS E ENGENHARIA.
}

DOI: 10.37702/2175-957X.COBENGE.2021.3439

Ana Paula Mattos - anapmattos@ufpa.br

Universidade Federal do Pará UFPA

Travessa 14 Abril 1489

66063-005 - Belém - PA

Claudia Aline da Silva Brabo - claudiaalinesilva9@gmail.com

Universidade Federal do Pará

Condomínio Viver Ananindeua 201

67030-325 - ANANINDEUA - PA

Alexsandra Iglesias Pereira - ale.iglesiasp89@gmail.com

UFPA

Passagem Marajoara Um 64b

66110-270 - Belém - PA

Luiza Marlene Oliveira Dias - luiza.dias@itec.ufpa.br

UFPA

Conjunto Tauari Quadra 5 Casa 5555

67125-060 - Belém - PA

Thaissa Toyomi Rocha Ueoka - Thaissa.ueoka@itec.ufpa.br UFPA

Rua João Coelho 1733

68790-000 - Santa Izabel do Pará - PA

Jullyane Raquel Almeida Nunes - Jullyane.nunes@itec.ufpa.br UFPA

Conjunto Catalina, travessa Sargento Muniz 101

66640-180 - Belém - PA

Alícia de Almeida Maia - aliciaengcomp@gmail.com

UFPA

Travessa Aratanha 10 
68790-000 - Santa Isabel do Pará - PA

Marina Letícia Leite Damasceno - marina.damasceno@itec.ufpa.br

Universidade Federal do Pará

rua mariano 14

66645-415 - Belém - PA

Renata Benaion Silva Do Vale - renata.vale@itec.ufpa.br

Universidade Federal do Pará

Conjunto Maguari Alameda oito 14

66823-068 - Belém - PA

FABIANA CARDOSO LEITE - fabicardoso19ufpa@gmail.com

ESTUDANTE

RUA ALACID NUNES, INDEPENDENTE 651

68795-000 - BENEVIDES - PA

Cybelle Ynara da Costa Silva - Cybelle.ynara@gmail.com

Universidade Federal do Pará

Cidade nova 8 we 43352

67133-260 - Ananindeua - PA

Resumo: Projetos de extensão voltados para mulheres nas carreiras de ciência, de tecnologia, de engenharia e de matemática (STEM) nas universidades é crescente, devido a necessidade de incentivo às meninas do ensino fundamental e ensino médio a ingressarem nessas áreas nas universidades, e ao mesmo tempo para o apoio e a capacitação das alunas nas universidades a não desistirem do curso. $\mathrm{Na}$ maioria dos cursos de engenharia são formados por homens, na região amazônica há um grande déficit de profissionais femininas nessas áreas, visando um amparo às alunas da UFPA e um maior engajamento com a comunidade, principalmente escolas da rede pública, promoveu-se dois projetos, um voltado para a robótica, o laçá, o qual o foco é desenvolvimento de tecnologia, competição em torneio de robôs e levar o conhecimento de conceitos de programação, robótica e eletrônica de maneira simplificada para as escolas. Outro projeto é o STEAMS UFPA, o qual desenvolve oficinas temáticas com temas de STEAM e sustentabilidade, as oficinas são oferecidas pelas próprias alunas voluntárias. Em ambos projetos há graduandas dos cursos de engenharia mecânica, de alimentos, biomédica e computação. Os dois projetos são formados por mulheres cujo o intuito é a representatividade e capacitação das discentes, além de estimular o interesse pela 
tecnologia. Nas poucas edições dos projetos na UFPA, observou-se um desenvolvimento de algumas habilidades nas voluntárias, tais como: escrita, comunicação e maior engajamento. Espera-se que com a interação nas escolas o número de meninas interessadas nas carreiras STEM aumente cada vez mais na região amazônica.

Palavras-chave: Robótica. STEM. Representatividade. Mulheres. Tecnologia. Oficinas. 


\section{INTRODUÇÃO}

Os projetos de extensão possibilitam a formação do profissional cidadão e credencia-se, cada vez mais, junto à sociedade como espaço privilegiado de produção do conhecimento significativo para a superação das desigualdades sociais existentes.

A Extensão Universitária tem um papel de suma importância a cumprir na integração dos avanços gerados na Universidade com a sociedade em geral. Essas ações têm ainda um grande potencial de divulgação científica, uma vez que podem levar a informação científica de uma forma facilmente assimilável para toda a população. Mas para que isso aconteça, a Extensão tem objetivo de comportar-se no setor inovador no organismo universitário (RAMIREZ, 2017).

A busca por equidade de gênero no mercado de trabalho e até mesmo no meio acadêmico, é considerada uma das principais pautas discutidas/reivindicadas na sociedade contemporânea. Historicamente, as funções destinadas às mulheres eram estritamente ligadas ao cuidado do lar e da família, e, em detrimento disso, observou-se um distanciamento significativo de mulheres no meio criativo e intelectual (CABRAL; BAZZO, 2008).

Ao longo da história, a luta de mulheres do mundo todo na conquista por mais espaços na sociedade foi marcada por preconceitos, discriminações, desigualdades, falta de oportunidades e falsas premissas. Alegações falaciosas foram empregadas como mecanismo de barramento de inclusão e ascensão de mulheres no espaço laboral e científico, as argumentações adotadas pressupunham falta de adaptabilidade ou até mesmo uma inferioridade intelectual de mulheres, legitimando assim, a exclusão destas em espaços onde a presença masculina era preeminente.

No Brasil, o cenário não foi diferente, o acesso à escolaridade foi marcado por desigualdades de gênero, raça e classe social. Pode-se dizer que, a partir de 1970 foi possível visualizar uma modificação considerável na composição de todos os níveis educacionais. De acordo com (BARROSO e MELLO, 1975), as mulheres representavam a maioria entre os alunos que concluíram o ensino médio no Brasil, com uma participação expressiva no curso normal. Todavia, aqueles indivíduos que não possuíam um currículo de orientação mais acadêmica tinham suas opções de ingressos ao ensino superior limitadas.

Neste contexto, a desigualdade de gênero, de acesso e da permanência no ensino superior são pontos relevantes a serem discutidos com as alunas de graduação e o incentivo às alunas do ensino médio a ingressarem nos cursos de engenharia. Um estudo da Cátedra Unesco Mulher, Ciência e Tecnologia na América latina (Flacso-Argentina), de 2018, revela que 9 em 10 meninas de 8 a 9 anos acreditam que engenharia "é coisa de menino". Um reflexo do estímulo e procura de meninas pelas ciências exatas é a Olimpíada Brasileira de Matemática nas Escolas Públicas disputada em 2018, apenas 30\% dos medalhistas no ensino fundamental eram garotas e a proporção ficou menor, na casa dos $20 \%$, entre os participantes do ensino médio (MARQUES, 2020).

Nos dias atuais, é possível verificar uma maior participação do público feminino em toda a esfera educacional, em decorrência de políticas públicas de democratização do acesso a esses espaços. Em 2019, segundo o Instituto Nacional de Estudos e Pesquisas (INEP) (INEP, 2018), no Brasil a maior parcela de ingressantes na universidade é do sexo feminino (57\%) e de concluintes também (61\%) (Figura 1). 
Figura 1 - Percentual de mulheres e homens matriculados e concluintes.

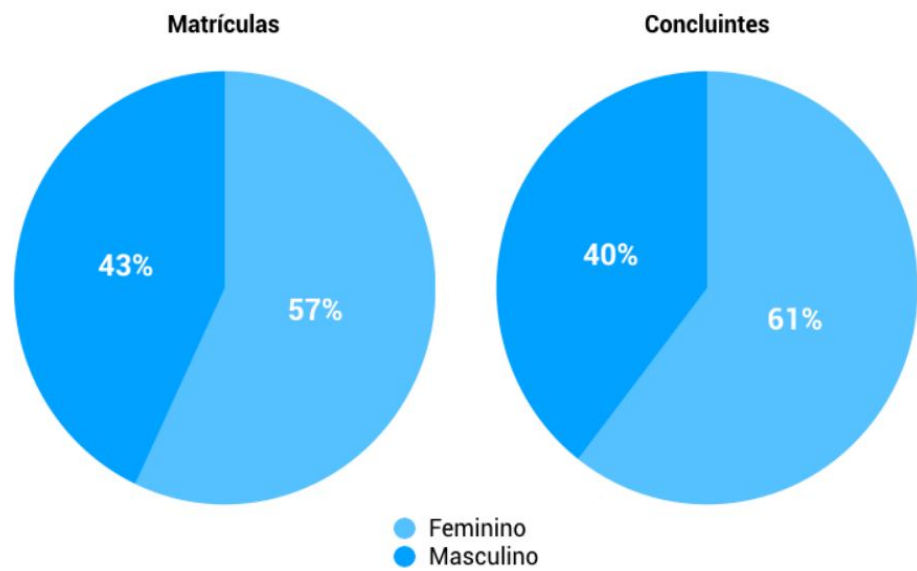

Fonte: INEP, 2018.

Porém, nos cursos de ciências exatas, segundo Marques (2020) a proporção de homens é bem maior, não somente no Brasil como Argentina, Espanha, México, Japão dentre outros países (Figura 2). Há carreiras dominadas por homens, por exemplo, em matemática e engenharia, enquanto outras, como enfermagem e pedagogia, permanecem majoritariamente femininas. Segundo um estudo desenvolvido pela Elsevier observaramse os autores de 15 países, entre 2014 e 2015, e o Brasil aparece entre as nações mais equânimes, com 0,8 mulher por homem (ante 0,55 no período de 1999 a 2003). O desempenho só foi superado por Portugal $(0,9)$ e Argentina (pouco mais de 1 mulher por homem), mas ficou à frente do Reino Unido $(0,6)$, dos Estados Unidos e da Alemanha $(0,5)$ (MARQUES, 2020).

Figura 2 - Número de matrículas na educação profissional segundo faixa etária e sexo - Brasil 2018.

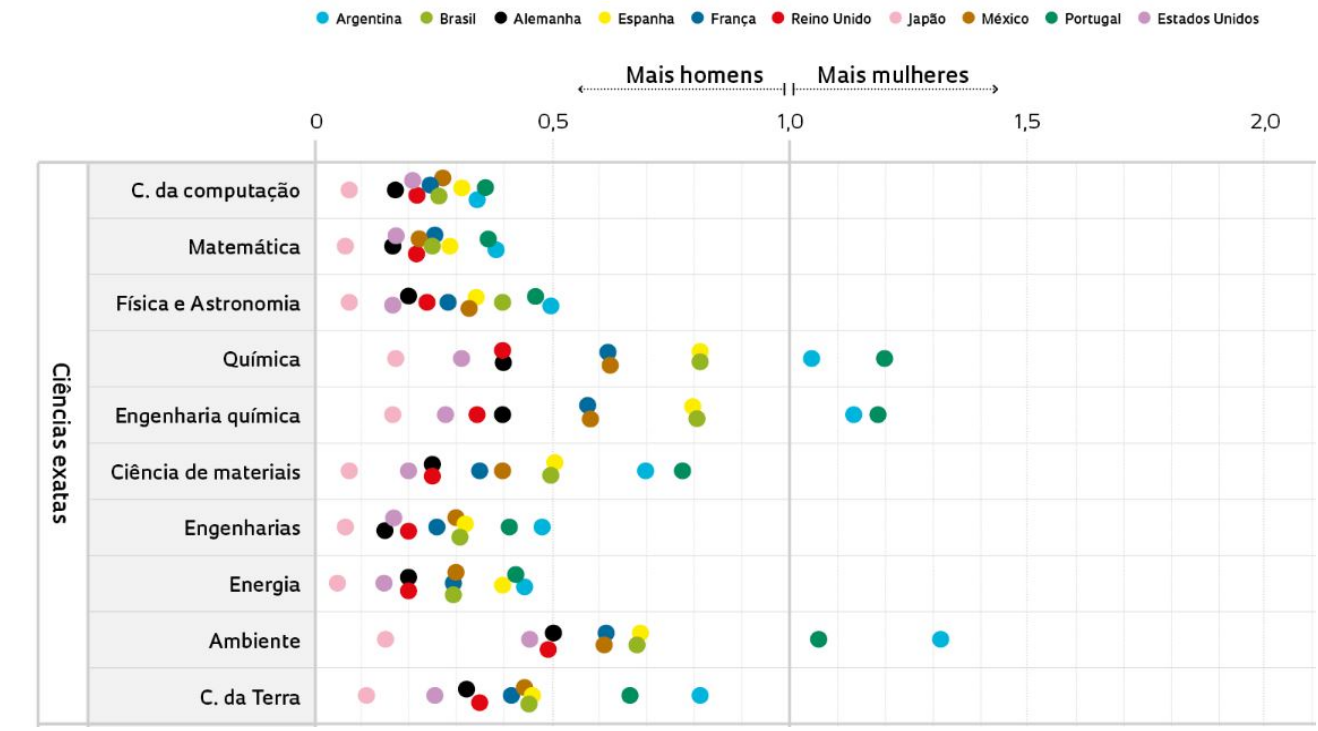

Fonte: MARQUES, 2020.

Em 1990 o número de homens na liderança de grupos de pesquisa no país era o dobro, na estatística mais recente de 2016 divulgado pelo Conselho Nacional de Desenvolvimento Científico e Tecnológico (CNPq) em 2016, mostra que a vantagem masculina caiu para 15\% (Marques, 2020). 
Segundo dados obtidos do Conselho Nacional de Desenvolvimento Científico e Tecnológico (CNPq), entre os anos de 2000 e 2016, referente ao número de bolsas concedidas a pesquisadores nos diretórios dos grupos de pesquisa, a Figura 3 apresenta uma crescente participação das mulheres.

A inclusão de mulheres em universidades sempre foi desafiadora, e há um grande déficit de formação de profissionais nas áreas de engenharia (MILHOMEM, PEREIRA, et al., 2014). Se tratando de profissionais do sexo feminino a situação é ainda mais preocupante. Apesar de nos últimos anos ter-se observado um grande avanço da mão de obra feminina nos diversos ramos da indústria, avançando rumo à equidade de raça $e$ gênero.

Figura 3 - Avanço das mulheres com bola na CNPq, (em milhares).

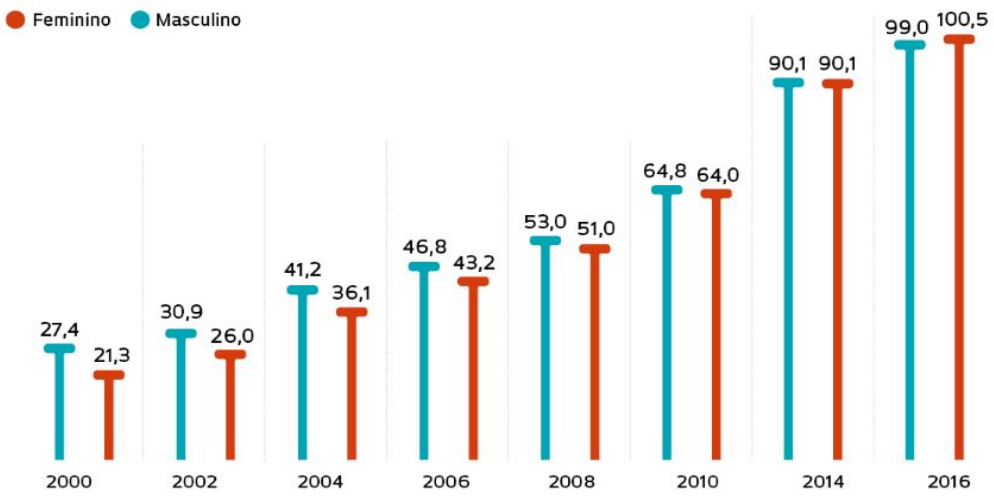

Fonte: MARQUES, 2020.

Segundo CNPq, até 2016 , cerca de $24,6 \%$ das bolsas de iniciação científica são de mulheres, mesmo representando a maior parte dos alunos de graduação. Na USP, em 1997, as mulheres representavam $4 \%$, atualmente são $19,4 \%$. Na pós-graduação, mestrado e doutorado, na área da engenharia, as mulheres não representam $5 \% \mathrm{em}$ relação aos outros cursos (Figura 4) (VENTURINI, 2017).

Figura 4 - Proporção de mestres e doutores segundo sexo e grande área.

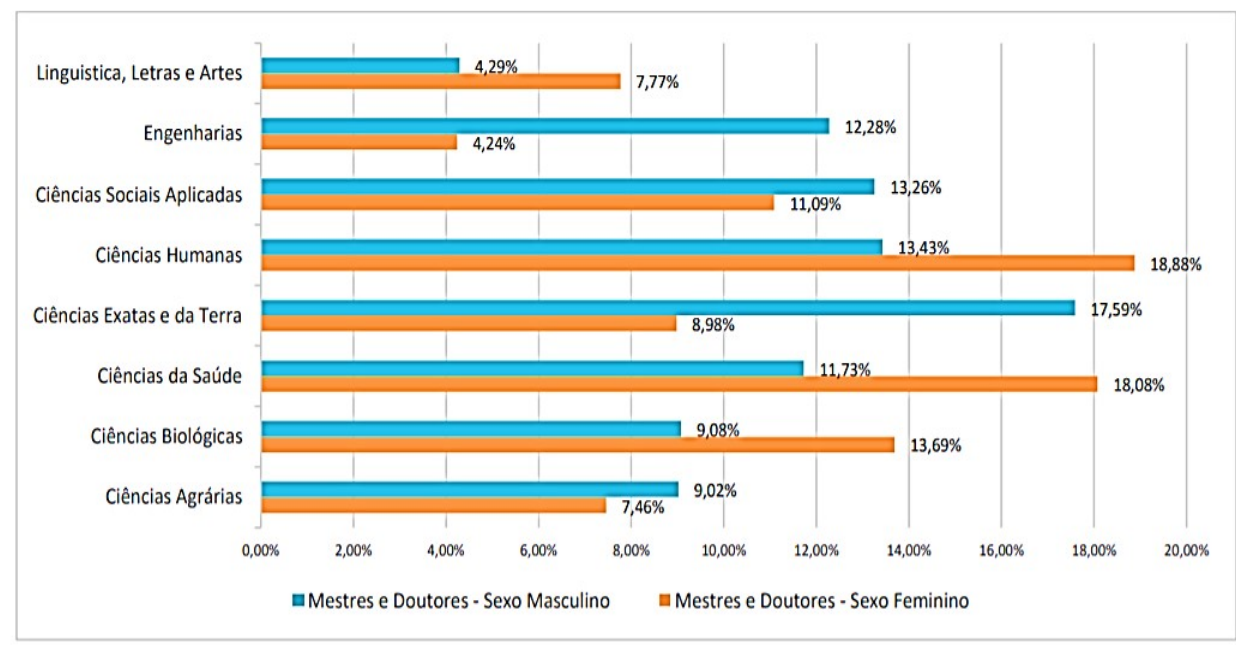

Fonte: VENTURINI, 2017. 
Dados da Coordenação de Aperfeiçoamento de Pessoal de Nível Superior (CAPES), outra fundação no Brasil que financia projetos de pesquisa, mostram também está discrepância, nos títulos de doutorados em 2017, onde 33\% foi obtida por mulheres nas engenharias, já nas ciências da saúde, letras o percentual varia de 60\% a 65\% (Figura 5).

Figura 5 - Distribuição de doutores concluinte em 2017 pela CAPES dividido por sexo e a áreas.

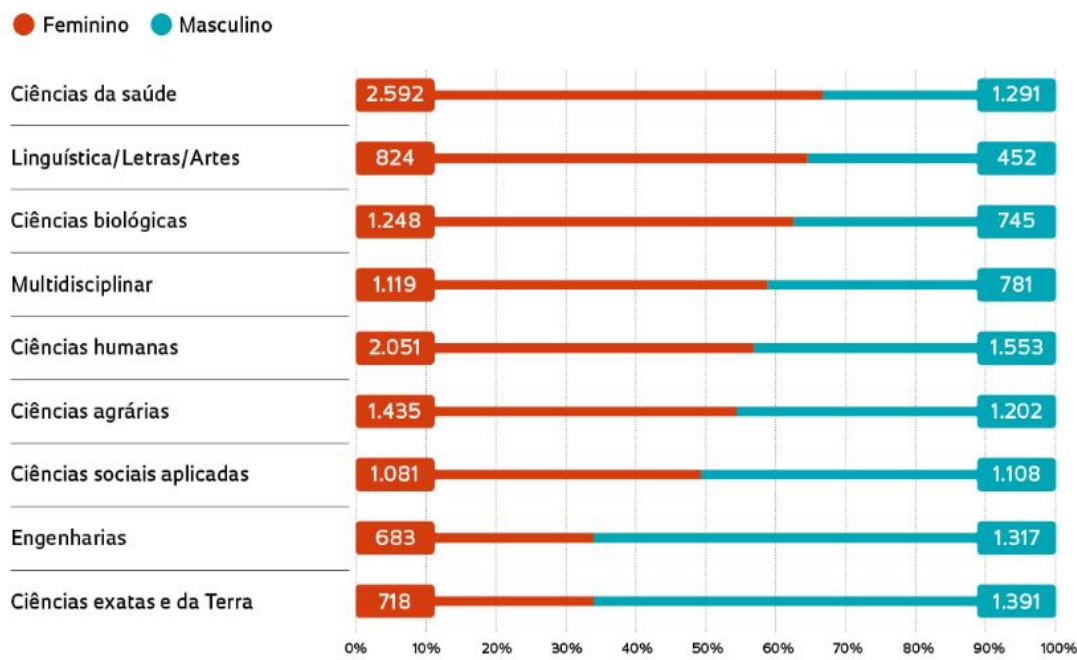

Fonte: MARQUES, 2020.

Quando se amplia a análise de mulheres pretas, pardas e indígenas o cenário é crítico e discrepante, pois sua presença em cursos de graduação e pós graduação é um processo histórico de exclusão. Na distribuição por raça/cor e sexo dos doutores pretas, pardas e indígenas é ainda menor: em torno de três vezes menor à média nacional para pretos e pardos, mesmo tendo a maioria da população brasileira que se declara pretos ou pardos (VENTURINI, 2017).

Na mesma realidade é possível verificar na UFPA, onde tem-se que $25 \%$ do curso de engenharia mecânica e de engenharia elétrica $20 \%$ são formados por mulheres em 2018. A Figura 6 apresenta a porcentagem de mulheres que ingressaram em cursos de engenharia na UFPA em 2020.

Figura 6 - Ingressantes na UFPA em 2020 nos cursos de engenharia.

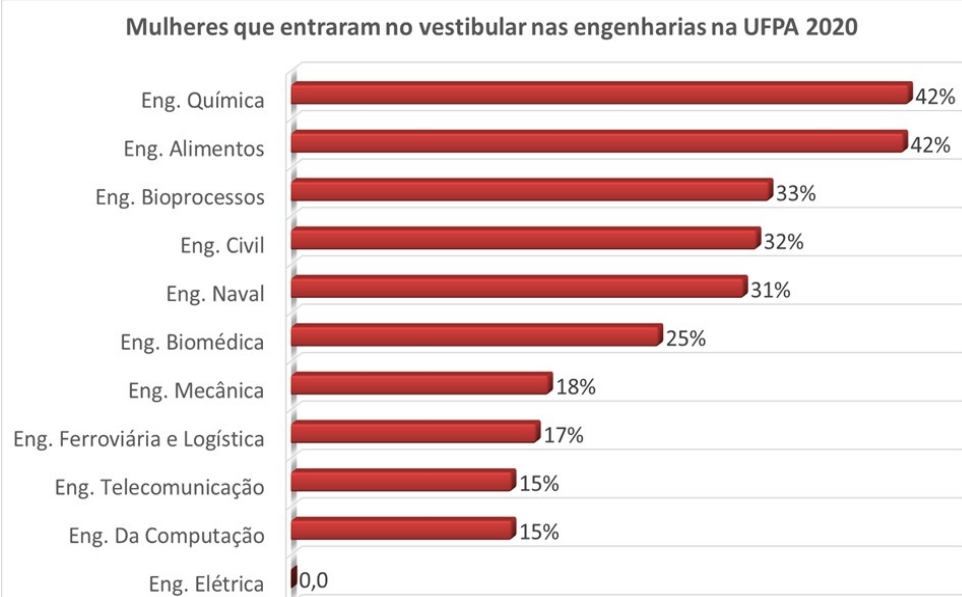

Fonte: Autor. 
Mediante ao exposto este artigo visa apresentar dois projetos de extensão da engenharia mecânica da UFPA, os quais trabalham com incentivo de meninas que cursam ensino fundamental e ensino médio de escolas públicas, estreitando o universo da universidade com a comunidade, e ao mesmo tempo amparam e desenvolvem habilidades nas voluntárias pertencentes do projeto, alunas de engenharia.

\section{PROJETOS DE EXTENSÃO VOLTADOS PARA MULHERES}

No intuito de aumentar o interesse de meninas da região amazônica, especialmente de bairros com alta vulnerabilidade social em Belém, dois projetos de extensão da UFPA, focam em desenvolver atividades que envolvam meio ambiente, ciência, tecnologia, engenharia e matemática (STEM).

\section{$2.1 \quad$ PROJETO STEAMS}

Em 2015, na Assembleia Geral da ONU, estabeleceram-se práticas a serem adotadas pelos países membros em pró do desenvolvimento sustentável no mundo, a qual determinou a Agenda 2030. Nela estão presentes os 17 Objetivos de Desenvolvimento Sustentável (ODS), dentre eles o ODS 4 tem como objetivo assegurar a educação inclusiva, equitativa e de qualidade para promover oportunidades de aprendizagem ao longo da vida de todos. E o ODS 5, alcançar a igualdade de gênero e empoderar mulheres e meninas.

O projeto STEMS UFPA, foi criado em 2019, conciliando a sigla STEM com o "S" de sustentabilidade, atualmente o projeto transformou-se e tornou-se STEAMS UFPA, acrescentando um "A", o qual se refere a arte, pois entendeu-se que projetos multidisciplinares e com diversos tipos de público solidifica conceitos empregados e aumenta o alcance do projeto. Neste segundo ano de execução, o projeto também visa abrir vagas para portadores de necessidades especiais e pessoas LGBTQIA+, os quais assim como as mulheres, também lutam por espaço e respeito.

O projeto nasceu com dois principais objetivos, o primeiro é incentivar e proporcionar o crescimento pessoal e profissional das discentes que cursam engenharia na UFPA. O segundo objetivo é incentivar meninas da rede pública do ensino fundamental e ensino médio a cursarem as carreiras STEM. Desta maneira concilia-se a representatividade, incentivo para meninas do ensino fundamental e ensino médio vendo outras universitárias ministrando as oficinas, e ao mesmo tempo demonstra a importância da disseminação do conhecimento e do papel da mulher no desenvolvimento da sociedade e de tecnologias. As oficinas idealizadas pelas voluntárias e professoras apresentam conceitos envolvendo STEAMS, as quais desenvolvem habilidades nas voluntárias e são instrumento de incentivo para as alunas das escolas. A educação 4.0 é a forma de descrever a nova didática dentro de sala, em referência a indústria 4.0, onde o uso da tecnologia é o foco principal (Noemi, 2018). Nessa nova metodologia, a base tecnológica é primordial para preparar os estudantes para o novo mercado de inserção.

O STEAMS é um projeto de extensão da engenharia mecânica, porém possui voluntárias também da engenharia biomédica e engenharia alimentos, totalizando 8 , neste ano de 2021, em 2020 eram 10. Atualmente o projeto consta com uma escola parceira no bairro Guamá de Belém, uns dos bairros mais vulneráveis da cidade. Pretende-se aumentar as escolas parceiras para que o alcance do projeto seja maior, o que só não ocorreu devido à pandemia do COVID-19. A qual está trazendo barreiras no engajamento com as alunas das escolas públicas, as quais em sua maioria não possuem acesso à internet ou 
computador para que possam desenvolver atividades virtuais, além das dificuldades encontradas pelas famílias.

O ensino e a aprendizagem pelo método STEM carrega a busca pela compreensão e pelo real impacto das disciplinas no mundo. Um dos grandes objetivos desse modelo de ensino é preparar estudantes do ensino médio para as universidades e mercado de trabalho.

O método STEM modifica não só o ambiente escolar assim como o familiar. Apresenta-se como algumas das principais frentes que o STEM contribui para a educação (TECNOLOGIA EDUCACIONAL, 2021):

1. Desenvolver uma sociedade "antenada" e capacitada em Ciências, Tecnologia, Engenharia e Matemática.

2. Formar alunos e professores que sejam capazes de desenvolver as competências do século XXI dentro de um ambiente integrado.

3. Gerar uma força de pesquisa e desenvolvimento em STEM voltada para inovação. Além destes fatores ligados ao ensino, tem-se também outros fatores:

- Fator psicológico: Percepção de concordância entre as características pessoais (aptidões, interesses pessoais, etc.) e os requisitos da formação e profissões do âmbito STEM.

- Fator Social: Percepção social das profissões técnico-científicas.

- Fator informativo: Conhecimento das possibilidades de trabalho no setor técnicocientífico.

O conceito STEM é aplicado no mundo todo, cada um voltado para uma área específica. No Reino Unido tem-se o STEMnet, o qual aplica uma plataforma que engloba escolas, docentes e profissionais de apoio ao STEM. No Canadá tem o projeto JUMP Math Metodologia do ensino de matemática para o primário e ciclo inicial do ensino secundário. Seu procedimento consegue o máximo desempenho de todos os alunos e de seus docentes como instrutores da matéria. No Egito, tem-se o CORD Mediante, uma competição que desafia os jovens a desenvolverem um robô utilizando materiais de uso cotidiano em seu contexto ou de baixo custo. Inclui oficinas interativas com instrutores voluntários.

No Reino Unido também há um sólido programa anual de atividades e eventos para conectar a sociedade civil à ciência (British Science Association), no Brasil o CDI (Committee for Democracy in Information Technology), o qual gera espaços informais ligados às instituições e líderes da comunidade que combinam a inclusão e educação tecnológica com a formação em cidadania e empreendimento.

O avanço contínuo da tecnologia muda constantemente nosso meio de ensino e de interação, integrar as áreas desenvolvendo o aluno para as mudanças é importante, tornando-o capacitado para uma nova sociedade mais sustentável e inclusiva. O projeto STEMS visa atender 6 ODS e conciliar o ensino 4.0, a fim de alcançar os objetivos do projeto, por meio das atividades:

\section{OFICINAS TEMÁTICAS:}

O projeto visa aplicar a metodologia STEAMS em suas oficinas, os quais possuem as 5 etapas: Investigar; Descobrir; Conectar; Criar; Refletir.

Toda instituição de ensino pode incrementar a metodologia STEAM, apesar de a tecnologia ser de extrema importância para o encaminhamento das atividades, o acesso a ela não é fácil em todas as regiões, desse modo se faz necessário inovar para exercer as atividades. O professor (as voluntárias do projeto), nesse caso, vira mediador, aquele cuja a função é instigar, questionar e incentivar o aluno para o objetivo principal que está sendo 
levantado, o aluno, por outro lado, assume a independência de solucionar problemas, de colocar em prática seus conhecimentos adquiridos, junto com uma equipe, ao passo que aprende a colaborar e ouvir, respeitando as diversas opiniões do grupo. Além disso, fazendo uso dos meios tecnológicos na resolução de um problema no qual possui matemática e ciência como base, assim intercalando conhecimentos adquiridos em sala de aula em contextos interdisciplinares.

Os assuntos contemplados pelas oficinas são: sustentabilidade, elétrica, programação com Arduino, eficiência energética e conceitos de física.

Sustentabilidade aplicada ao reaproveitamento de alimentos, compostagem, vaso auto irrigável, confecção de luminárias com materiais de reciclagem. Conciliando com conceitos de: tecnologia que é o projeto de irrigação de horta a partir de Arduino, eficiência energética, elétrica básica. Conceitos de física, como ondas e imagem com experiência de foto na lata.

No intuito de trazer os pais para conhecer o universo da universidade e ao mesmo tempo aproximá-los do projeto, pretende-se realizar uma oficina de Economia Doméstica para que auxilie as famílias a se planejarem, diminuírem os descartes, além do letramento digital, utilizando o celular e/ou computador.

As Figuras 7 e 8 apresentam partes dos experimentos já montados pelo projeto, onde inicialmente ensinou-se e reforçou conceitos básicos de eletricidade para as voluntárias para montar os kits para as oficinas (Figura 7). A oficina foi idealizada a partir de materiais de baixo custo: leds, resistores, pilhas.

Em uma outra oficina idealizada, as voluntárias montaram composteiras com materiais recicláveis de baixo custo (Figura 8), para ensinar conceitos de reciclagem, aproveitamentos de resíduos orgânicos, e posteriormente será inserido os conceitos de horta orgânica com irrigação por Arduino, o qual será uma outra oficina do projeto. Em todas oficinas são empregados conceitos os quais desenvolvem a parte técnica das voluntárias, habilidades pessoais e ao mesmo tempo servem para incentivar as meninas das escolas, apresentando de maneira simples conceitos STEM.

Figura 7 - Experiência de Circuito elétrico, acionamento de buzina (liga e desliga) e led.

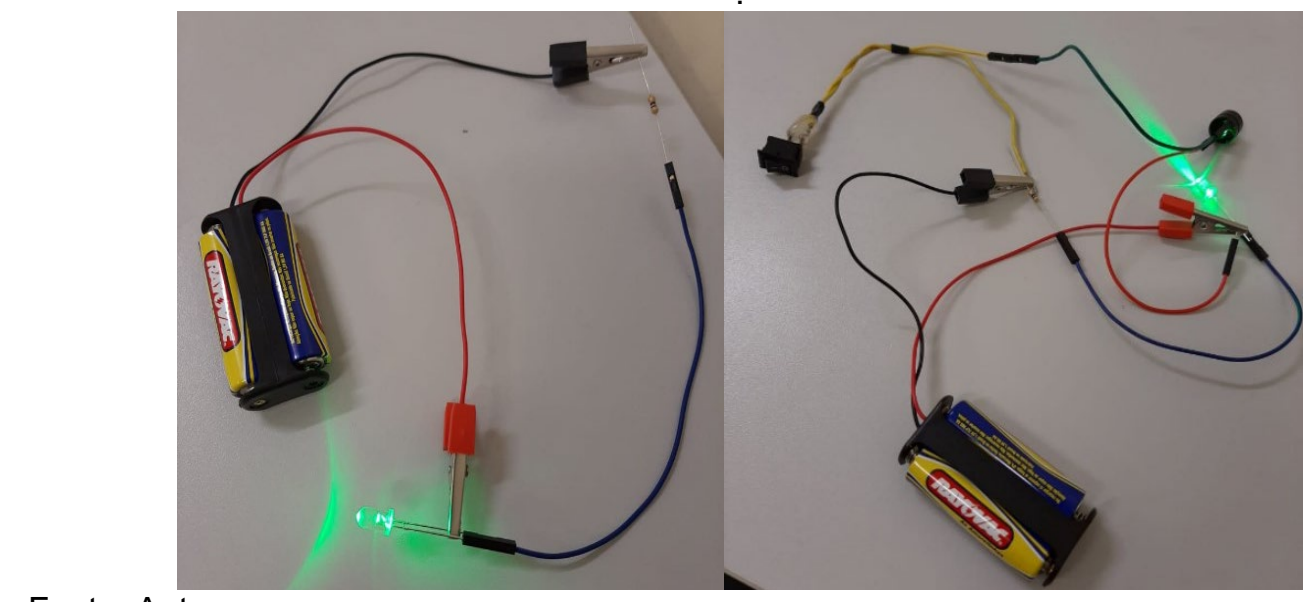

Fonte: Autor. 
Figura 8 - Experiência de compostagem e reaproveitamento de alimentos.

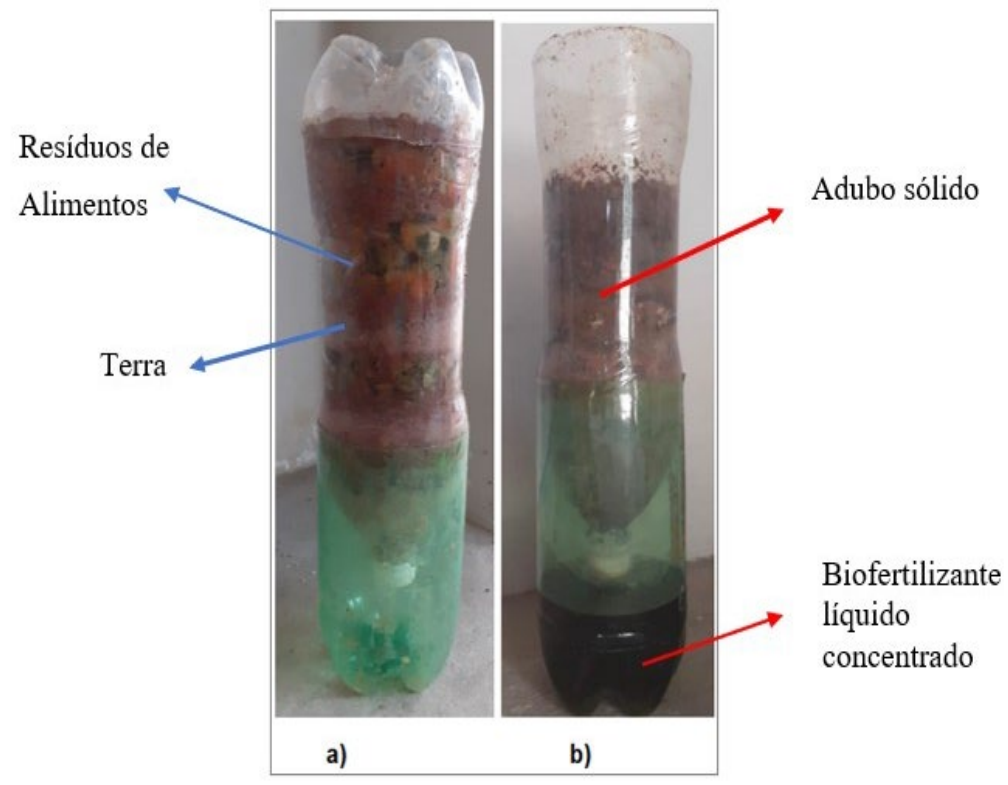

Fonte: Autor.

\section{EVENTOS:}

No início do isolamento, promoveu-se o Desafio STEMS Em Casa, por meio da rede social Instagram, que iniciou entre as professoras e alunas do projeto, cada qual realizou uma experiência, com materiais de baixo custo, demonstrando como a ciência, tecnologia e engenharia estão no nosso cotidiano. Experimentos como: indicação de pH com repolho roxo, holograma com CD transparente, oscilação de ondas pela voz usando lata, funcionamento de termelétrica, extração de DNA da banana. Também se aplicou arte e sustentabilidade com vaso auto irrigável e confecção de porta retrato.

O projeto iniciou o STEMS Te Ajuda no ENEM, em que as voluntárias resolveram questões do exame em vídeos, que foram postadas no Instagram e canal do YouTube, além de elaborar uma apostila a ser distribuída para algumas escolas públicas, de modo a ajudar os alunos que não possuem acesso à internet.

Durante o ano de 2020 tiveram palestras com temas de engenharia e mulher, a fim de debater e levar conhecimento para a comunidade sobre a importância do projeto e do tema.

Neste ano também serão realizadas palestras, lives com temas científicos e que abordam o papel da mulher na sociedade.

Realizou-se um evento online em prol do dia 11 de fevereiro, Dia internacional das Mulheres e Meninas na Ciência, o projeto promoveu palestras de empoderamento feminino, com os temas: Empreendedorismo, Mulheres na área de TI, Grupo de robótica e outros projetos de extensão que incentivam as alunas da área de exatas na Universidade. As palestras foram online por meio do YouTube, abertas ao público, tendo como alvo as alunas de graduação e do ensino médio. Também contou com um minicurso de programação Android pelo aplicativo Inventor, ministrado por parceiros do projeto. A Figura 9 apresenta uma coletânea de fotos das atividades realizadas pelo projeto.

Em abril, iniciará um minicurso online de introdução ao Excel, o qual as voluntárias dos projetos ensinarão funções, fórmulas e gráficos para aqueles que estejam ingressando na universidade, assim como para toda comunidade. Também temos projetos de oficina de 
metodologia científica. E oficinas onde se possa trabalhar e desenvolver habilidades nas voluntárias, que as capacitem para o mercado de trabalho.

Figura 9 - Coletânea de fotos de eventos realizados pelo projeto em 2020 e 2021.

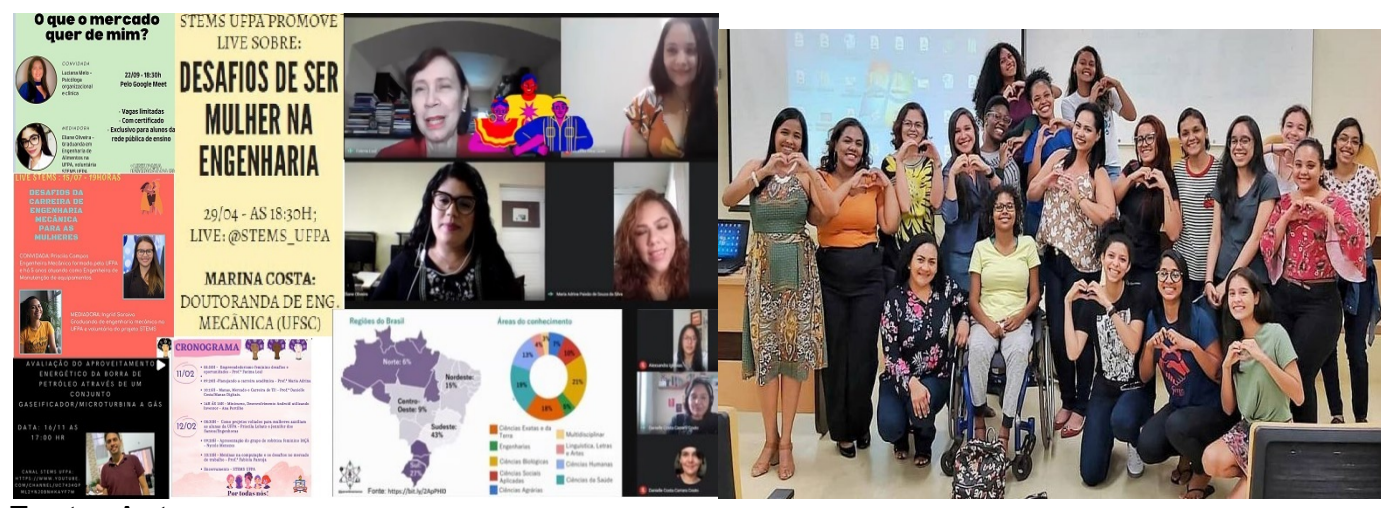

Fonte: Autor.

\subsection{PROJETO IAÇÁ}

No mesmo propósito do STEAMS, o projeto IAÇÁ se tornou projeto de extensão em 2021 a fim de levar conhecimentos de robótica para as meninas e ser um canal de representatividade de mulheres em desenvolvimento de tecnologia na região Norte. Atualmente, é composto por 15 integrantes (Figura 10) divididos para as tarefas de liderança, marketing, controle financeiro e de projetos. As voluntárias são dos cursos de engenharia da computação, engenharia mecânica, engenharia biomédica, engenharia de telecomunicações e Tecnologia em Geoprocessamento.

Figura 10 - Reunião virtual do projeto laçá.

Fonte: Autor.

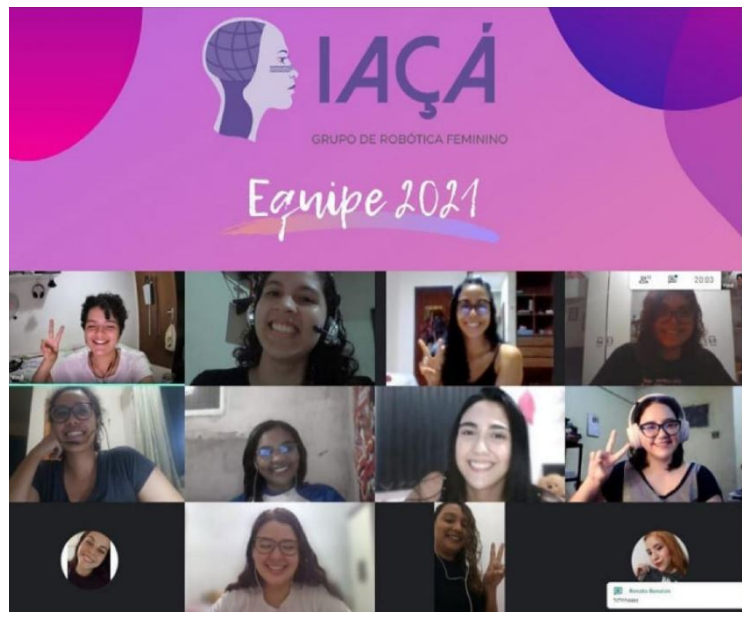

O laçá é também um Grupo de Afinidade IEEE Women in Engineering (WIE) UFPA, o qual visa proporcionar às estudantes da graduação a oportunidade de fazer parte de pesquisas teóricas e de projetos práticos, servindo como um centro de desenvolvimento de novas pesquisas e encorajando a participação feminina nas áreas de robótica, engenharia e tecnologia, bem como, em eventos e competições nacionais e internacionais. Em 2019, o grupo desenvolveu um robô seguidor de linha, o qual utiliza sensores infravermelho, motor DC e servo motor (Figura 11). 
Figura 11 - Robô criado pelo grupo em 2019.

Fonte: Autor.

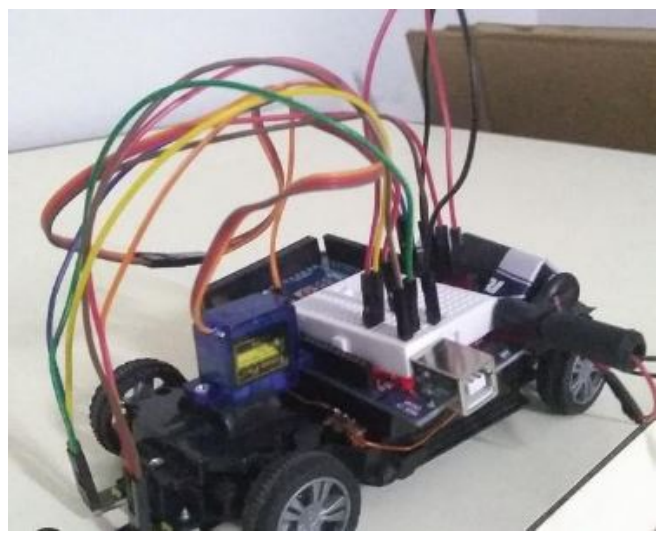

A utilização da robótica na sala de aula tem os seguintes objetivos para com os alunos: o desenvolver a autonomia, isto é, ter a capacidade de se expressar, de se posicionar e de elaborar projetos pessoais; o desenvolver a capacidade de trabalhar em grupo, respeitando a diversidade de opiniões; o desenvolver a capacidade de encontrar soluções para problemas; o desenvolver capacidades e competências ligadas à lógica, noção espacial, pensamento matemático; o promover a interdisciplinaridade entre as várias ciências, história, geografia e artes (OLIVEIRA, 2018).

O projeto pretende desenvolver atividades de projetos de pesquisa tais como: a construção da impressora 3D para auxiliar na construção dos robôs e como forma de ganhar recursos para investir no grupo e a construção de robôs de linha, a priori para a competição. Pois um dos objetivos do grupo é a participação em eventos de robótica que decorrem ao longo do ano, mas o foco será a participação no Robocup. Portanto, o grupo será dividido conforme as áreas de afinidade de cada integrante, e dessas áreas constarão a eletrônica, a mecânica e a programação. No desenvolvimento dos robôs serão utilizadas as linguagens de programação: $\mathrm{C}$ e $\mathrm{C}++$, amplamente utilizadas na programação de sistemas embarcados, como por exemplo, a plataforma de desenvolvimento Arduino. Visando estes objetivos, em abril e março é realizada uma capacitação com as novas integrantes, apresentando conceitos de lógica de programação, eletrônica básica e mecânica voltada para a modelagem, esta atividade é desenvolvida pelas voluntárias mais antigas.

Ao longo do projeto, o IAÇÁ utilizará a metodologia ágil scrum para desenvolvimento e gerenciamento dos projetos, tendo ciclos (sprints) de duas semanas e reuniões uma vez por semana para acompanhamento de progresso de cada tarefa e atribuição de novas outras, além da utilização do trello para a criação do quadro kanban e administração das sprints (ciclos de trabalho) e o Google Meet para reuniões online.

Pretende-se também realizar oficinas e minicursos gratuitos, para membros e não membros da universidade, focado em meninas, mas é importante ressaltar que em ambos projetos não há exclusão de meninos, mas sim uma maior porcentagem de vagas dedicadas para meninas e mulheres. O primeiro minicurso que será realizado será de introdução ao Arduino, o qual será online e está sendo elaborado por duas voluntárias do projeto. O projeto está estabelecendo parcerias com ONG 's escolas para criar oficinas online de programação básica, e projetos de mini robôs. Todas essas atividades de integração serão feitas neste ano por meio das redes sociais, devido a pandemia. Porém, serão criados materiais de apoio e kits para quando as atividades presenciais voltarem e 
desta maneira estreitar ainda mais o universo da universidade, tecnologia com as escolas e ONG 's.

\section{Considerações FINAIS}

Projetos de extensão em universidades são caracterizados por desenvolver habilidades nos discentes, além das técnicas aprendidas em sala de aula, e nos últimos 10 anos projetos voltados para as mulheres são necessários para aumentar o número de meninas nas carreiras STEM, pois é evidente a majoritariedade masculina. O Brasil e principalmente a região norte são caracterizadas principalmente por uma maioria da população constituída por pretos, pardos e indígenas, quando une-se o sexo (feminino) e a cor, a discrepância da participação destas nas áreas STEM é ainda menor.

Mediante ao exposto os projetos STEAMS e laçá são importantes para a região e a universidade, pois oferecem apoio e capacitam as alunas das engenharias, principalmente as voluntárias, e ao mesmo tempo estas servem como representantes de mulheres pretas, pardas, indígenas desenvolvendo pesquisa e apresentando oficinas, minicursos levando conhecimento para toda comunidade. No projeto STEAM a maioria $(75 \%)$ das voluntárias se declaram pretas, pardas ou indígenas, no projeto laçá $(78 \%)$, isso demonstra que o projeto contribui para uma maior representatividade na região, pois ao mesmo tempo que se tem a maioria da população sendo pretas, pardas ou indígenas a minoria chega a cursar universidades, principalmente nos cursos STEM.

\section{REFERÊNCIAS}

BARROSO, Carmen Lúcia de Melo, MELLO, Guiomar Namo de. 0 acesso da mulher ao ensino superior brasileiro. Cadernos de Pesquisa, São Paulo, n. 15, 1975, p. 47-77, dez. 1975.

CÁTEDRA UNESCO MULHER. Ciência e Tecnologia na América Latina (FlacsoArgentina)". 2018. Disponível em: https://g1.globo.com/educacao/noticia/desdepequenas-meninas-ja-consideram-a-engenharia-uma-atividade-so-para-meninos-diz-

estudo.ghtml. Acesso em Fev.2020.

INEP. Censo Escolar: Mulheres são maioria na educação profissional e nos cursos de graduação. Março de 2019. Disponível em:http://inep.gov.br/artigo/lasset publisher/B4AQV9zFY7Bv/content/mulheres-sao-maioria-na-educacaoprofissional-e-nos-cursos-de-graduacao/21206. Acesso em 15 Abril de 2021.

MARQUES, Fabrício. A desigualdade escondida no equilíbrio. Revista Fapesp 2020. Edição 289. Disponível em: https://revistapesquisa.fapesp.br/a-desigualdade-escondidano-equilibrio/. Acesso em 18 de Abril 2021.

MILHOMEM P. Incentivando Mulheres Paraenses a cursarem Engenharia. In: CONGRESSO BRASILEIRO DE EDUCAÇÃO EM ENGENHARIA, XLII, 2014, Juiz de Fora - MG. 2014.

ONU. "Agenda 230". 2015. Disponível em: http://www.agenda2030.com.br/. Acesso em Março de 2021. 
OLIVEIRA, Ana Paula Naveca Brito. Uma investigação sobre a utilização dos kits de robótica em escolas municipais da zona sul de Manaus. Trabalho de conclusão de curso da Universidade do Estado do Amazonas. 2018

RAMIREZ M. A., E. Schettini, e M. Cunha. Avaliação das ações de Extensão Universitária sob a perspectiva do público-alvo: o Índice de Impacto Social, no. 2, pp. 230-244, 2017.

TECNOLOGIA EDUCACIONAL. 2021. "O que é STEM ou STEAM?" Disponível em: https://tecnologia.educacional.com.br/blog-habilidades-sec-xxi/steam-ou-steam-o-quesao-e-no-que-se-diferenciam/. ._Acesso em Fev. de 2021.

VENTURINI Anna Carolina. A presença das mulheres nas universidades brasileiras: um panorama de desigualdade. $13^{\circ}$ Mundo de mulheres e Fazendo Gênero 11 transformação, conexões e deslocamento. 2014.

\title{
EXTENSION PROJECTS AS A TOOL FOR A GREATER PARTICIPATION OF WOMEN IN EXACT SCIENCES AND ENGINEERING COURSES.
}

\begin{abstract}
Extension projects aimed at women in science, technology, engineering, and mathematics (STEM) careers in universities is growing, due to the need to encourage girls from elementary school and high school to enter these areas in universities, and at the same time for the support and training of female students in universities not to give up the course. In the Amazon region, there is a great deficit of female professionals in these areas, aiming to support female students at UFPA and a greater engagement with the community, especially public schools, two projects were promoted, one focused on robotics, the laçá, which focuses on technology development, competition in robotics tournaments and taking the knowledge of programming concepts, robotics, and electronics to schools in a simplified way. Another project is STEAMS UFPA, which develops thematic workshops with STEAM and sustainability themes. In both projects, there are undergraduate students from the mechanical engineering, food, biomedical, and computer engineering courses. Both projects are formed by women whose intention is the representation and empowerment of female students, besides stimulating their interest in technology. In the few editions of the projects at UFPA, we have observed the development of some skills in the volunteers, such as writing, communication, and greater engagement. It is hoped that with the interaction in schools the number of girls interested in STEM careers will increase more and more in the Amazon region.
\end{abstract}

Keywords: Robotics. STEM. Representativeness. Women. Technology. Workshops. 